\title{
PRRSV ERADICATION ON LARGE-SCALE FATTENING PIG FARMS IN HUNGARY BETWEEN 2014 AND 2019
}

\author{
István SZABÓ $^{1 *}$, Tamás MOLNÁR ${ }^{1}$, Imre NEMES ${ }^{1}$, Tamás ABONYI ${ }^{1}$, Zsolt TERJÉK $^{1}$ \\ and Ádám BÁLINT ${ }^{2}$ \\ ${ }^{1}$ National PRRS Eradication Committee; ${ }^{2}$ Department of Virology, National Food Chain \\ Safety Office Veterinary Diagnostic Directorate, Tábornok u. 2, H-1143 Budapest, \\ Hungary
}

(Received 24 July 2019; accepted 20 October 2019)

Eradication of porcine reproductive and respiratory syndrome virus (PRRSV) from the pig population of Hungary started in 2014 on the basis of the territorial principle. In order to reach this goal it was crucial to render each fattening unit free of this disease, since fattening units play a significant role in spreading the virus all over the country. In 2015, 188 out of 307 large-scale fattening farms $(61.2 \%)$ kept PRRS-positive animals. The main source of infection of these farms was the import of PRRS-infected fattening pigs. The following methods were used during the eradication from 2017: (1) Only pigs coming from PRRSfree farms were allowed to be used for fattening in Hungary; (2) Quarantine of all herds for 60 days; (3) PCR test for PRRS 48 hours after the arrival of the prefattening animals; (4) Serological test for PRRS at the end of the quarantine period. If any diagnostic test gave even one positive result and the result was confirmed by another test, the stock had to be sold for slaughter within 15 days or placed outside Hungary, so that the infected stock would not compromise the PRRS status of that area. PRRSV eradication on large-scale fattening units applying all-in/all-out operation was relatively simple, using the depopulation-repopulation method. On permanently operating farms, the infected herd was sold from time to time, without having to be repopulated until the last delivery. After cleaning, disinfection and restocking, the repopulation was done with PRRS-free animals. As the eradication progressed over the years, a ban on the import of infected fattening pigs was imposed. As a consequence of these measures, by the end of 2018, Hungarian large-scale fattening farms became free of PRRS. Maintaining the national-level PRRS-free status of large-scale pig fattening units contributes to eliminating a significant cost factor from the Hungarian pork production industry, and opens the way for a significant reduction in antibiotic consumption as well.

Key words: PRRS, eradication, large-scale swine herds, Hungary

*Corresponding author; E-mail: balintad@nebih.gov.hu; Phone: 0036 (30) 984-5102

Open Access. This is an open-access article distributed under the terms of the Creative Commons AttributionNonCommercial 4.0 International License (https://creativecommons.org/licenses/by-nc/4.0/), which permits unrestricted use, distribution, and reproduction in any medium for non-commercial purposes, provided the original author and source are credited, a link to the CC License is provided, and changes - if any - are indicated. 
In the course of porcine reproductive and respiratory syndrome (PRRS) eradication from the pig population in Hungary, production of fattening pigs traditionally takes place in three different forms: the major part is still produced by large, specialised, so-called 'farrow-to-finish' pig farms. In recent years, the type of large-scale breeding herds has appeared where only weaned piglet or prefattening production is carried out at the breeding establishment, and either prefattening or fattening is performed at other holdings, frequently run by a different owner (multi-site system). In the case of large-scale fattening farms (with a minimum of 100 pigs/holding) (Anonymous, 1997), the raw material may originate from the same holding, from other herds of Hungary and sometimes from abroad. The pre-fattened pigs may come from the above-mentioned three sources.

At the same time, although in a drastically decreasing number, individual farmers (keeping 1-10, mostly fattening pigs, produced for family consumption) still remained in the system.

The large-scale fattening farms operate in two different ways: all-in/all-out system or continuous operation sites.

The vast majority of pigs slaughtered in Hungary are produced from farrow to slaughter and, to a less extent, from farrow to wean or from farrow to prebreed farms. In addition, there are animals for slaughter produced in large-scale fattening farms, or fatteners coming from abroad. Having these figures, the number of the slaughtered pigs per breeding sow kept in Hungary can be estimated with a high probability.

According to the slaughterhouse data (Table 1), the average liveweight of a pig at slaughter is $111-114 \mathrm{~kg}$ and the carcass weight is $90-92 \mathrm{~kg}$.

Pork consumption per capita in Hungary significantly declined in the 1990 s, and since the 2000s pork and poultry meat has accounted, in an equal ratio, for $90 \%$ of the meat consumption of the Hungarian population. Domestic pork consumption per person was $29.3 \mathrm{~kg}$ on average in 2016-2018 (Central Statistical Office of Hungary, 2019).

According to the animal health legislation in force, the pig population of large-scale Hungarian fattening pigs is free from swine brucellosis, leptospirosis and Aujeszky's disease. During the production period, infectious respiratory and enteric diseases are the main source of economic losses. Among the respiratory diseases, PRRS is the most important (Holtkamp et al., 2013). Due to the endemic presence of infectious diseases in these herds during production, antibiotic consumption is usually very high compared to the European average (European Surveillance of Veterinary Antimicrobial Consumption, ESVAC). Based on this report, antibiotic consumption in Hungary is $459 \%$ compared to that of Denmark.

Hungary launched a compulsory National PRRS Eradication Programme in 2014. As part of the Pork Strategy (Anonymous, 2012) issued by the Government in 2012, the National PRRS Eradication Programme that was unique among the EU Member States has for the first time introduced a national pro- 
gramme that can help the Hungarian pig sector to become an effective, profitable and competitive member of the global swine market.

The legal framework for the eradication programme is the $3 / 2014$ (I. 16.) VM decree (Anonymous, 2014), which came into force after consultation with experts from the pig sector. On the basis of the decree, the EU commission responsible for PRRS also approved the National PRRS Eradication Programme.

The implementation of the tasks set out in the decree was based on uniform principles, and was regulated by the National PRRS Eradication Plan. The Minister of State for Food Chain Supervision and Agricultural Administration of the Ministry of Rural Development, the National Chief Veterinary Officer of the Ministry of Rural Development appointed the National PRRS Eradication Committee in order to establish the professional measures arising during the programme. Furthermore, the Committee formulates and comments on professional measures and policy, and provides support for the decision-making process of the national authorities [National Food Chain Safety Office (NÉBIH), Food Chain Safety and Veterinary Directorate (ÉBÁI), and the District Veterinary Offices]. In this paper, we present the results of the PRRS Eradication Programme carried out on large-scale fattening pig farms in Hungary.

\section{Materials and methods}

During the period of 2014-2016, in the 'Assessment Phase', reliable and accurate data of the Hungarian fattening herds were obtained: their origin, location, number of places for fattening, the technology used, the origin of pigs, their infection and PRRS status. During this period, large-scale fattening farms in the areas subjected to eradication were classified based on their PRRS status. After removing the pigs followed by careful cleaning and disinfection of the premises, only PRRS-free animals were allowed to be repopulated.

The second, 'Eradication Phase' of the process began on the basis of the Decision of the National Chief Veterinary Officer published in November 2017 (Anonymous, 2017). The decision banned the import of non-PRRS-free fattening stocks to Hungary for fattening, so that only PRRS-free nursery pigs could be used for fattening. By 30 June 2018, according to the decision, all Hungarian large-scale fattening pig farms had to be certified for PRRS freedom. From the second half of 2018, taking into account the need to eradicate the disease from large breeding establishments, we have stabilised the PRRS status of large-scale fattening farms, and we paid special attention to those farms that had not reached PRRS-free status yet for different reasons ('Freedom Maintenance Phase'). The farms that used prefatteners from PRRS-infected large breeding establishments had to apply disease control measures ensuring that the herd in question did not pose a risk of infection to non-infected flocks in their environment. 
The following methods were used in all three phases of the eradication:

(1) Quarantine of all herds for 60 days;

(2) PCR test (Virotype PRRSV RT-PCR Kit (Qiagen, Germany) according to the manufacturer's instructions) for PRRS 48 hours after the arrival of the prefattening animals;

(3) Serological test [PRRS Universal ELISA Kit (Ingenasa) according to the recommendations of the producer] for PRRS at the end of the quarantine period.

In 2017, as part of the 'Eradication Phase', based on the decision of the National Chief Veterinary Officer (Anonymous, 2017):

(1) Only pigs coming from PRRS free farms were allowed to be used for fattening in Hungary;

(2) If any diagnostic test after 48 hours of arrival, or after 60 days of quarantine gave even one positive result, a second test [indirect immunofluorescence test (IIF); Anonymous, 2015] had to be carried out, and if it gave the same result, the stock had to be sold for slaughter within 15 days or placed outside Hungary, so that the infected stock would not compromise the PRRS status of that area.

The tests required for the classification of large-scale fattening farms for PRRS were laid down in 3/2014 (I. 16.) VM Regulation (Anonymous, 2014). When all the animals arrived from an officially free stock, blood samples were taken based on $95 \%$ confidence at $10 \%$ prevalence, evenly distributed within the stable representing the whole population. The herd may be declared free based on serological testing. Pigs arriving from non-certified herds were serologically examined in the same way but at 5\% prevalence. Until any positive laboratory test the herd could keep its PRRS-free status.

Samples that proved positive in the serological tests were subjected to PCR for PRRSV. In case of PCR positivity, sequencing of the ORF5 gene of PRRSV was carried out, and if it was not successful, ORF7 sequencing was done. ORF5 sequences detailed in the Results section were submitted to the GenBank under the following Accession Numbers: MN150534-MN150540 and MN102128MN102334. Based on the sequence data, the 'similarity network' image was performed (Szabó et al., manuscript), and the sequences were classified as described by Shi et al. (2010) and Balka et al. (2018). For the similarity network representation, we involved 2,583 PRRSV ORF5 sequences identified in Hungary from 2003. Based on this similarity network, we determined case by case the most probable source of introduction of PRRSV to a certain infected swine herd.

\section{Results}

\section{Distribution of pigs imported to Hungary from EU member states}

Between 2014 and 2016, the ratio of fattener shipments (the average number of imported fatteners was more than 600,000, and imported slaughter pigs were almost half million per year) arriving to Hungary from non-PRRS-free 
farms was $50-60 \%$. PRRS viruses introduced into Hungary via imports spread significantly and threatened the PRRS status of Hungarian large-scale breeding, fattening and small-scale farms.

In 2015, 188 (61.2\%) out of 307 large-scale fattening farms registered by the Hungarian veterinary authorities kept PRRS-positive animals. Of the total number of fattening places on these farms, $63.9 \%$ was PRRS positive (Table 3). At national level, there was no significant difference in the number of infected and free stocks per holding.

In $2013,46 \%$ of pigs coming to Hungary as fatteners originated from the Netherlands, 39\% from Germany, and 12\% from Slovakia. The rest arrived from Denmark, Austria, the Czech Republic and Slovenia. In 2016, the Netherlands accounted for $46 \%$, Germany for $33 \%$, Denmark for $10 \%$ and Slovakia for $6 \%$ of imports of fatteners to Hungary (Table 2).

\section{Pigs imported from The Netherlands}

The prefatteners from the Netherlands came to Hungary through two wholesale companies into Komárom-Esztergom County. One of them maintained its production by operation of farms of prefattening pigs in both Hungary and the Netherlands. The Hungarian breeding establishment and its separated fattening unit were free of PRRS.

The other two large-scale fattening farms in the group imported the prefatteners from the Netherlands produced on its own site. Practically in all consignments PCR and sequencing detected wild-type viruses that were responsible for PRRS infection on the Dutch farm and these viruses clustered with other Dutch import viruses representing two different genetic clades (PRRSV1 clade 1A and PRRSV1 clade $1 \mathrm{~F}$ that was highly similar to the Lelystad reference strain). The pig herds on the Dutch breeding site were vaccinated with the Porcilis PRRS (MSD) vaccine, so the virus strain of the vaccine was found several times in samples from the imported animals.

The Hungarian fattening farm, which housed the fatteners from the vaccinated breeding flock infected with PRRS in the Netherlands, applied proper biosecurity measures ensuring that the import of PRRS virus from infected pigs did not result in any case in infection of other Hungarian pig farms.

In 2018, the company group established a so-called 'fourfold free' (meaning brucellosis, Aujeszky's disease, leptospirosis and PRRS free) breeding establishment in Hungary and since then all of its Hungarian fattening farms have met the PRRS freedom requirements.

All Dutch companies owned by other enterprises (by the initial letters of their names: Ko., Cr., K-A B., L. and partner sites: Eg., Ne.) had PRRS infected status. These pigs were transported to Hungary at 4 weeks of age, where they were adapted to the local conditions for 30 days in different settlements. They were taken to large-scale fattening farms in different parts of the country at 60 days of age. In these cases, the 60-day quarantine period was carried out at two separate sites. 

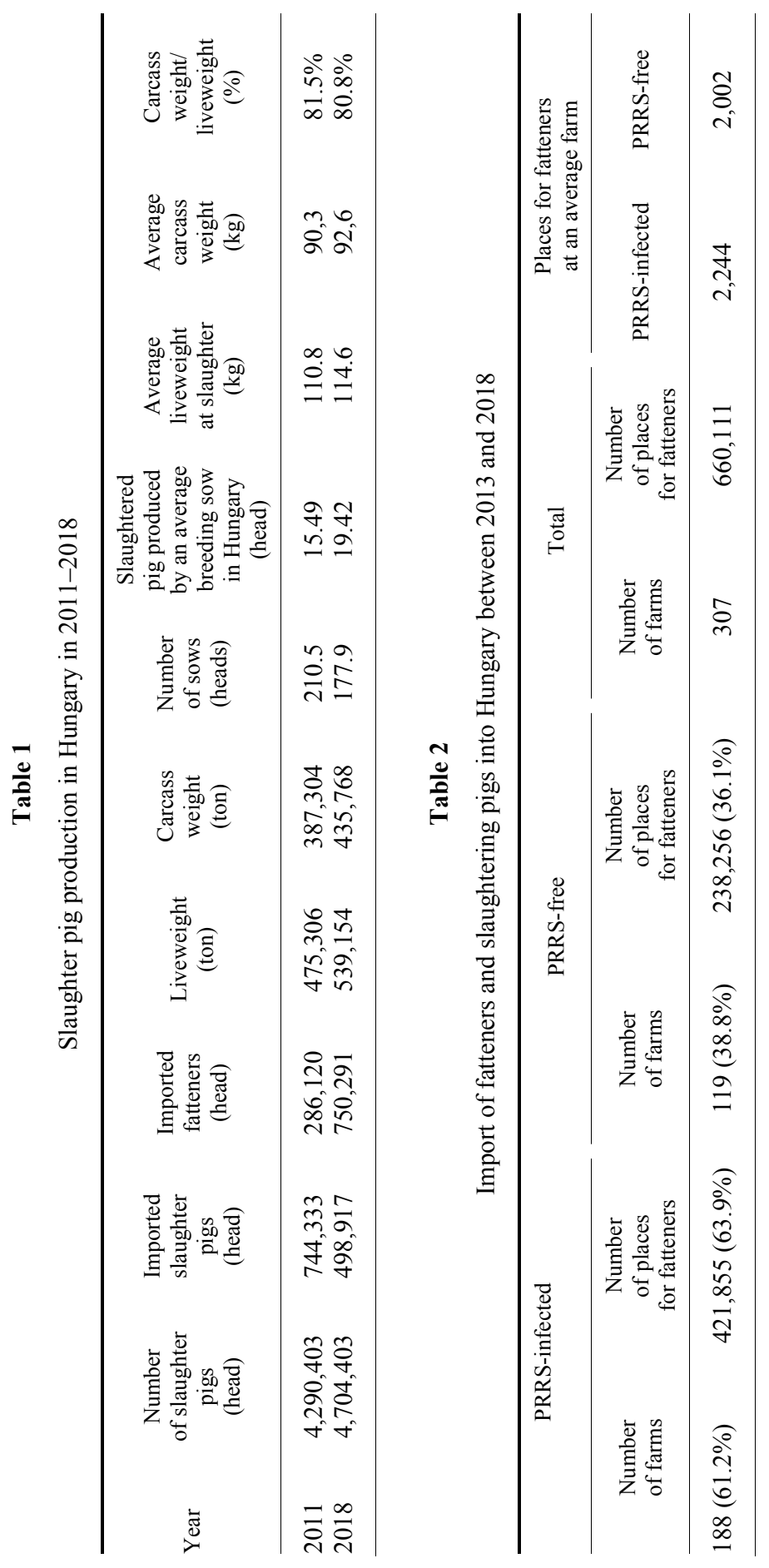


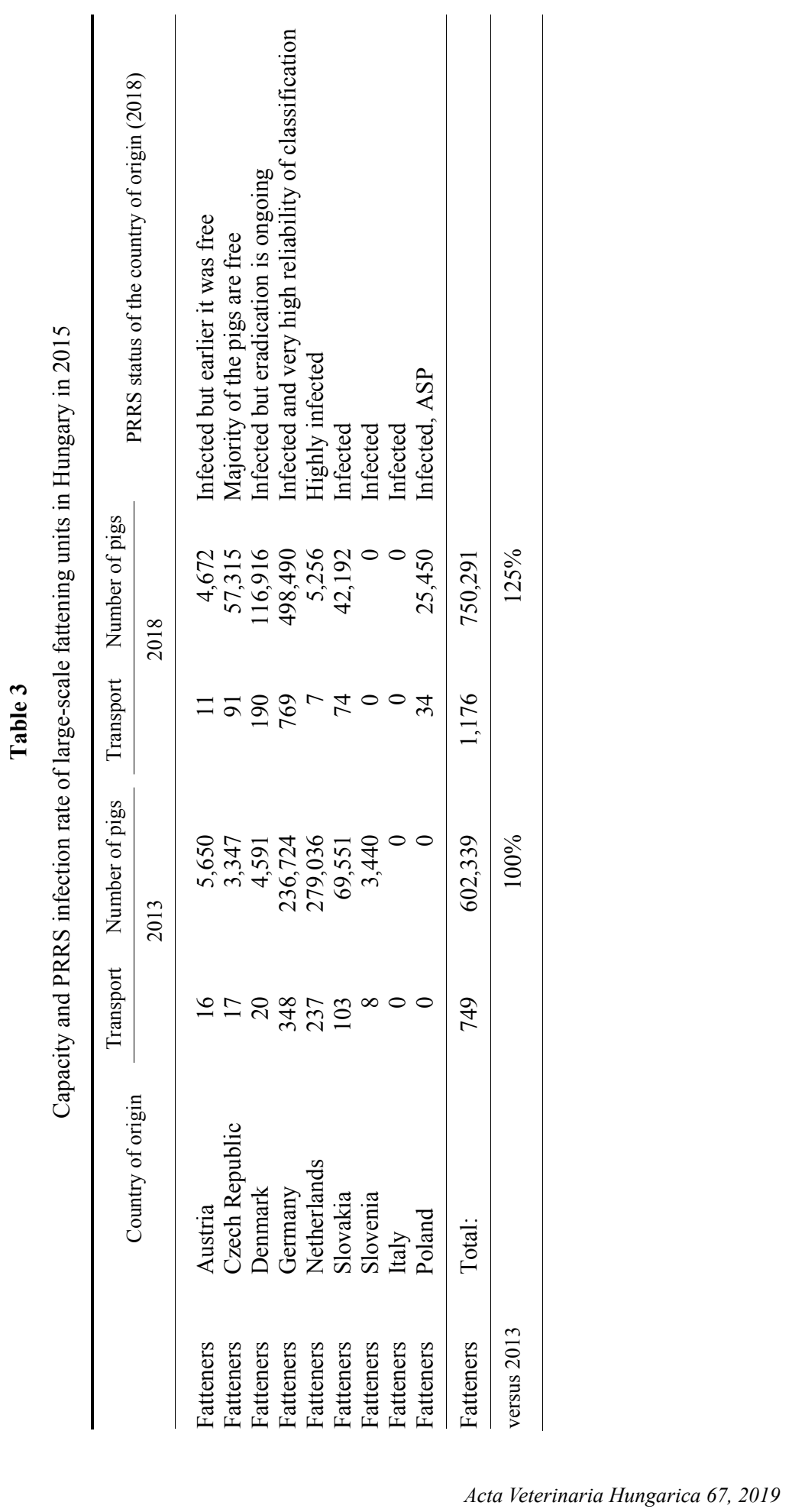


In case of one of the farms of the company group, potentially PRRSnegative weaned piglets were sent to Hungary which originated from the Dutch breeding stock vaccinated against PRRS a long time (nearly one and a half years) ago. The chosen piglets with continuous supply were placed in a 18,000 -seat plant in Hungary. Within 48 hours after arrival in Hungary, the laboratory testing of piglets for PRRS (PCR) was performed in all cases. PRRS virus free status was confirmed at the end of the quarantine period (90 days of age) by PRRS serological test based on $95 \%$ confidence at $5 \%$ prevalence. This procedure, from the end of 2015 to December 2016, resulted in the production of more than 80,000 PRRS-free pigs.

At the end of 2016, a company in the Netherlands, infected with another PRRS virus, caused infection of many Hungarian herds, and these viruses formed a unique unassigned clade. Later on, further Dutch farms of the company were infected, and in 2017 PRRS virus arrived in Hungary with pigs from these farms. This virus (28370 NEBIH 2017 HU) was not only the source of the PRRS infection for a large number of fattening farms, but also for several large breeding farms, and these viruses formed a well-defined group within clade $1 \mathrm{G}$. In the case of a large breeding establishment, the infection occurred due to non-compliance with the disease control rules. Not more than 10 meters isolation distance was between the PRRS-free large breeding facility and the PRRS-infected fatteners that arrived from the Dutch farm.

\section{Pigs imported from Slovakia}

A significant number of fatteners arrived from Slovakia. Slovakian import animals have been shown to be infected several times both with different wildtype and vaccine PRRS viruses.

A PRRSV2 lineage 5 (Shi et al., 2010) live modified vaccine virus containing the US strain used on these farms appeared in the importing large-scale fattening farms in Hungary (50708 NEBIH $2014 \mathrm{HU}$ ). The vaccine in question is neither authorised nor registered in Hungary.

The same Hungarian farms were infected with another PRRS virus strain that had previously been detected in Slovakia (KC522643_13M_2007_SVK, a PRRSV1 Clade C lineage 1g strain). This virus strain (8727 NEBIH $2016 \mathrm{HU})$ has also been introduced to Hungary by import of fatteners.

In an unknown way this virus infected one of the largest domestic (Hungarian) swine integrator, located near the Slovakian border. Owned by one of the largest Hungarian integrators, its three large-scale, from breeding to nursery, PRRSinfected breeding farms significantly contributed to the PRRS infection of large Hungarian fattening herds. The fattening pigs derived from these herds and subsequently arriving in the fattening integration resulted in a high level of infection. From 2017 onwards, the company has implemented a depopulation-repopulation 
eradication programme at all three sites, and from the beginning of 2019, only PRRS-free prefattened animals will be introduced into the integration.

\section{Pigs imported from Denmark}

According to the Danish rules of exporting fatteners from Denmark to Hungary, the Danish partner had to certify that the animals are free from PRRS at farm level. In Denmark the only possible way to load the fatteners on the pig farms was if the truck was only in the green zone within 7 days before loading. Since Hungary, Slovakia and the Czech Republic belonged to the red zone, pigs could be loaded only from an EU-certified loading station (collecting station).

The animals were transported as follows: from the Danish breeding establishment the Danish lorry (internal transport) carried the pigs to the collection station. There, after a certain time, the pigs were transferred to the truck transporting them to Hungary. This truck was checked and disinfected with a certificate prior to entry to Denmark. The animals were then transported to the place where they were kept in Hungary within 24 hours.

In many cases, during their stay at that collecting station, pigs from PRRSinfected and free herds were kept in the same air space, so they could be infected with various PRRS viruses, although they had been reared in a PRRS-free plant.

In this way, Hungarian swine farms were infected with the aforementioned American modified live virus vaccine strain (32607 NEBIH 2017 HU and 55352 NEBIH 2018 HU) from Denmark.

In the same way, infection of Hungarian large-scale fattening units took place from Denmark with a European PRRS virus strain (36750 NEBIH 2017 HU).

As a consequence of these events, the largest Hungarian importer decided to continue the import of fattening animals only if the Danish partner accepts laboratory test results of the Hungarian National Reference Laboratory (NRL) for PRRS, the animals are investigated for PRRS (PCR and ELISA) 48 hours after arrival, and in the case of positivity of any PRRS test, the animals are transported at the expense of the exporter from the farm to the slaughterhouse or for fattening outside of Hungary. Using these rules, the number of PRRS-infected Danish fatteners decreased dramatically.

\section{Pigs imported from Germany}

As far as the import of fatteners from large-scale breeding pig farms is concerned, our experience showed that the practice of Germany was best suited to the Hungarian requirements. Although no official veterinary certificate was issued for PRRS status in the absence of appropriate regulation, due to the longterm partnership efforts, reliably free stocks arrived in Hungary for further processes. Shipments were usually accompanied by a certificate from the farmer or the official veterinarian. 


\section{The roles of the fattening unit in farrow-to finish herds}

The eradication of the virus from large breeding herds plays a pivotal role in the PRRS eradication programme. In Hungary, $80-85 \%$ of the large-scale pig breeding farms are farrow to finish ones. Our experience shows that primarily the infection and the significant virus shedding of the animals in the fattening units are responsible for the continuous presence of PRRS virus at these sites. This virus shedding is usually so high that it is not possible to maintain the PRRS-free status of progeny and to reach a virus-free state of the pigs during the entire duration of fattening. Therefore, the Decision of the Chief Veterinary Officer (Anonymous, 2017) created a new opportunity for herds that are able to produce piglets that are not infected by the end of nursery ( $70-80$ days of age). These animals could be transported into PRRS-free large-scale fattening herds.

This method required rigorous observation of the monitoring protocol, strict implementation of the quarantine rules and intensive co-operation between the different levels of the veterinary authorities. At the same time, it gave the breeding establishments an opportunity to accelerate the eradication process and at the same time significantly reduced the number of infected fattening units.

\section{Use of vaccines during the eradication process}

It is a remarkable experience that large-scale, continuously running fattening pig farms should be very careful about the use of live attenuated vaccines, as in these cases the vaccine virus will persist for a long time. This is illustrated by the decision of the management of a major Hungarian pig producing company. The company had a farrowing to nursery pig farm with a continuous flow of 1,000 sows, and three farms where the fatteners arrived. The strategy of PRRS eradication was to empty the breeding site by depopulation-repopulation process, and then gradually replace the fattening units. Following the introduction of PRRSV-free piglets, a live PRRS vaccine (ReproCyc, Boehringer Ingelheim, Germany) was used in one of the three fattening units. Unexpectedly, due to severe shortcomings of biosecurity measures on the farms the virus strain of the vaccine spread to the other two farms where no vaccination took place. The farms did not get rid of the vaccine virus during continuous operation. Later, in a transport related to a PRRSinfected pig farm, wild-virus infection occurred among fatteners, and both the wild-type and the vaccine PRRS virus strains were detected by laboratory methods in the herd. Subsequently, all three herds had to be replaced in order to obtain the PRRS-free herds.

\section{Current state of PRRS eradication in fatteners}

By the end of 2018, the majority of Hungarian large-scale fattening farms had become free of PRRS (Table 4). The remaining PRRS-infected farms are 
keeping animals originating from the latest infected sources, and are going to be free by 31 March 2019 .

Table 4

Number of PRRS-infected and PRRS-free fattening units in 2015-2018

\begin{tabular}{|c|c|c|c|c|c|}
\hline \multirow{3}{*}{ PRRS-infected } & \multirow{3}{*}{$\begin{array}{l}\text { Number of units } \\
\text { Places for fatteners }\end{array}$} & \multicolumn{2}{|c|}{2015} & \multicolumn{2}{|c|}{2018} \\
\hline & & 188 & $61.2 \%$ & 15 & $5.4 \%$ \\
\hline & & 421,855 & $63.9 \%$ & 55,482 & $9.3 \%$ \\
\hline \multirow{2}{*}{ PRRS-free } & Number of units & 119 & $38.8 \%$ & 264 & $94.6 \%$ \\
\hline & Places for fatteners & 238,256 & $36.1 \%$ & 542,432 & $90.7 \%$ \\
\hline \multirow{4}{*}{ Hungary } & Total units & \multicolumn{2}{|c|}{307} & \multicolumn{2}{|r|}{279} \\
\hline & Total places for fatteners & \multirow{2}{*}{\multicolumn{2}{|c|}{$\begin{array}{r}660,111 \\
2,244\end{array}$}} & \multicolumn{2}{|c|}{597,914} \\
\hline & PRRS-infected average heads/farm & & & \multicolumn{2}{|c|}{3,699} \\
\hline & PRRS-free average heads/farm & \multicolumn{2}{|c|}{2,002} & \multicolumn{2}{|c|}{2,055} \\
\hline
\end{tabular}

PRRS eradication from independent, large-scale fattening herds was carried out differently depending on the technology used. Where the all-in/all-out system was used, the infected stock was slaughtered and replaced with a PRRSfree herd. In farms using continuous production, the infected herd was sold from time to time, without having to be repopulated until the last delivery. After cleaning, disinfection and restocking, repopulation was done with PRRS-free animals.

PRRS eradication from large-scale fattening units induced major changes in Hungary for countries exporting pigs to Hungary: within a year, in 2018 compared to 2017 imports from the Netherlands fell from 216,316 to 5,256 (a 97.6\% decrease). There was also a significant decrease in the number of pigs imported from Denmark $(168,370$ to 116,916$)$ and from Slovakia $(71,576$ to 42,192$)$. As a result of the domestic regulations, all imports for fattening decreased significantly, by $24.2 \%$ (from 989,560 to 750,291 ) (Table 2 ).

\section{Discussion}

The eradication of PRRSV from the pig population of Hungary started in 2014 on the basis of territorial principle, and was gradually extended to all pig keepers by issuing the relevant regulation (Anonymous, 2014). One of the cornerstones of this process was the widespread opinion that the distance of airborne spread of PRRS virus is up to $9.1 \mathrm{~km}$ (Dee et al., 2009; Otake et al., 2010). Based on this data and considering that Hungary is a transit country concerning the transport of pigs it seemed doubtful whether PRRS could be eradicated. However, achieving PRRS-free status could bring significant economic benefits to Hungarian pig production (Holtkamp et al., 2013; Rathkjen et al., 2017). 
Based on this latter fact, experts in favour of implementing PRRS eradication from pigs in Hungary stressed that the traditions of pig keeping, the type of pig farms, the coexistence of small and large scale herds and the increase in the number of farms dealing with fattening, first and foremost requires knowledge of the spread of the disease in Hungary, under the special Hungarian swine-keeping circumstances and having this knowledge, a proper eradication strategy can be developed.

Accordingly, PRRS eradication from the Hungarian pig herds was carried out on a territorial basis from the beginning, with the immunisation of the animals, the implementation of strict biosecurity measures, the continuous application of serological and virological tests and the immediate epidemiological assessment of the results. In the case of the small-scale pig population, the annual monitoring surveys and the immediate removal of infected herds were extended to the whole country.

During PRRS eradication from large-scale herds, based on the extent and prevalence of the infection and the applied farm technology, specific methods were developed that are suitable not only for eradication but also for maintaining long-term PRRS-free status.

The eradication of PRRSV from large-scale fattening units plays an important role in the implementation of the whole eradication process. Of these, PRRS eradication from all-in/all-out operations is relatively simple, using the depopulation-repopulation method (infected stock $\rightarrow$ slaughterhouse $\rightarrow$ site cleaning and disinfection $\rightarrow$ new, PRRSV-free herd arrivals).

On permanently operating farms with a large number of animals, the process takes longer, and the cost of eradication is significantly higher. In this case, the complete depopulation and disinfection must be carried out on the farm, and only then can the repopulation (even continuously) be performed.

If there is a sufficient number of separated buildings (internal biosecurity) available on the farm, the gradual, non-simultaneous exchange of infected stocks of continuous operation sites is a professionally feasible procedure, but practical implementation is rather difficult. In these cases, the buildings from which the stock was sent to slaughter, and disinfection and restocking were done, will be repopulated, and the farm will try to continuously prevent the newly arriving PRRS-free stock from contamination by means of internal disease control methods (separate caretakers, equipment, feeding, etc.). The procedure continues as long as the last infected pig leaves the herd, and then free status can be achieved.

The efficacy and safety of the process implemented can be increased by vaccination of the infected stock in order to reduce viral shedding. Based on our previous results, the protection provided by inactivated vaccines is not sufficient to prevent the flock from infection if there is a lack of disease control. The PRRS live virus vaccine strain may also remain in the herd for a long time due to inadequate disease control measures, therefore no virus-free status can be achieved. 
In our experience, the only effective way of PRRS eradication for large numbers of fattening pigs in Hungary is the complete depopulation-repopulation.

Emphasis should be given to the continuous maintenance of PRRS-free status, the external biosecurity and reliable free status of the new, replacement herds. This was greatly facilitated by the repopulation of a fattening stock in Hungary derived exclusively from free stocks from November 2017.

An important element of the PRRS eradication programme is the maintenance of the free status of fattening stocks. At present, 124 of the 174 districts in the country have officially certified PRRS-free status. As this number is to steadily increase, it is very important that from large-scale breeding farms that are still under the PRRS eradication process, the fattening pigs produced during this procedure should be placed in such a way that they do not pose a risk of infection to the free herds in their environment. In these cases, regular, extensive laboratory testing of infected flocks, immunisation with the inactivated vaccine during the fattening phase and strict observation of disease control rules are of utmost importance. The most effective process we used was the immunisation of the infected breeding sow stock, the PCR analysis of piglets at the time of weaning, and then the negative serological test carried out at the age of 70-90 days. The placement to other farms of such individuals that have proven to be negative in the tests for at least 5 months can be successfully processed until they are slaughtered as a fattening stock without PRRS.

Maintaining the national-level PRRS-free status for large-scale pig fattening units means that in the long term, a significant cost factor in the production of Hungarian pork caused by PRRS has been removed, and this opens the way for a significant reduction in antibiotic consumption as well.

\section{References}

Anonymous (1997): Decree No. 41/1997 (V. 28.) of the Minister of Agriculture on issuing the Animal Health Regulation [in Hungarian].

Anonymous (2012): Decision No. 1323/2012 (VIII. 30.) of the Hungarian Government on the strategy of the swine industry in Hungary [in Hungarian]. Magyar Közlöny (Hungarian Gazette) 114, 19447.

Anonymous (2014): Decree No. 3/2014 (I. 16.) VM of the Minister of Rural Development on PRRS eradication of the swine population of Hungary [in Hungarian]. Magyar Közlöny (Hungarian Gazette) 3, 447.

Anonymous (2015): Porcine Reproductive and Respiratory Syndrome. Detection of antibodies with the indirect immunofluorescence assay. OIE Manual of Diagnostic Test and Vaccines for Terrestrial Animals, 2015. Chapter 3.8.6.B.2.2.

Anonymous (2017): Decision No. 7/2017 of the Chief Veterinary Officer of Hungary. Földmüvelésügyi Értesítő (Agricultural Reports) volume LXVII, number 12, 555.

Balka, G., Podgórska, K., Brar, M. S., Bálint, Á., Cadar, D., Celer, V., Dénes, L., Dirbakova, Z., Jedryczko, A., Márton, L., Novosel, D., Petrović, T., Sirakov, I., Szalay, D., Toplak, I., Leung, F. C. and Stadejek, T. (2018): Genetic diversity of PRRSV 1 in Central Eastern Europe in 1994-2014: origin and evolution of the virus in the region. Sci. Rep. 8, 7811. 
Central Statistical Office of Hungary (2019): Infraannual Data of Agriculture. (http://www.ksh.hu/ stadat_evkozi_4_1)

Dee, S., Otake, S., Oliveira, S. and Deen, J. (2009): Evidence of long distance airborne transport of porcine reproductive and respiratory syndrome virus and Mycoplasma hyopneumoniae. Vet. Res. 40, 39.

European Surveillance of Veterinary Antimicrobial Consumption (ESVAC): www.ema.europa.eu/ en/veterinary-regulatory/overview/antimicrobial-resistance/european-surveillance-veterinaryantimicrobial-consumption-esvac

Holtkamp, D. J., Kliebenstein, J. B., Neumann, E. J., Zimmerman, J. J., Rotto, H. F., Yoder, T. K., Wang, C., Yeske, P. E., Mowrer, C. L. and Haley, C. A. (2013): Assessment of the economic impact of porcine reproductive and respiratory syndrome virus on United States pork producers. J. Swine Health Prod. 21, 72-84.

Otake, S., Dee, S., Corzo, C., Oliveira, S. and Deen, J. (2010): Long-distance airborne transport of infectious PRRSV and Mycoplasma hyopneumoniae from a swine population infected with multiple viral variants. Vet. Microbiol. 145, 198-208.

Rathkjen, P. H. and Dall, J. (2017): Control and eradication of porcine reproductive and respiratory syndrome virus type 2 using a modified live type 2 vaccine in combination with a load, close, homogenise model: an area elimination study. Acta Vet. Scand. 59, 4.

Shi, M., Lam, T. T. Y., Hon, C. C., Murtaugh, M. P., Davies, P. R., Hui, R. K. H., Li, J., Wong, L. T. W., Yip, C. W. and Jiang, J. W. (2010): Phylogeny-based evolutionary, demographical, and geographical dissection of North American type 2 porcine reproductive and respiratory syndrome viruses. J. Virol. 84, 8700-8711.

Szabó, P. M., Szalay, D., Kecskeméti, S., Molnár, T., Szabó, I. and Bálint, Á. (2019): Investigations on spreading of PRRSV among swine herds by bioinformatics methods. Manuscript.

This is an open-access article distributed under the terms of the Creative Commons Attribution 4.0 International License (https://creativecommons.org/licenses/by/4.0/), which permits unrestricted use, distribution, and reproduction in any medium, provided the original author and source are credited, a link to the CC License is provided, and changes - if any - are indicated. (SID_1) 